\title{
Inside the Mind Reader's Tool Kit: Projection and Stereotyping in Mental State Inference
}

\author{
Daniel R. Ames \\ Columbia University
}

\begin{abstract}
Mental state inferences—judgments about what others think, want, and feel-are central to social life. Models of "mind reading" have considered main effects, including social projection and stereotyping, but have not specified the conditions that govern when these tools will be used. This article develops such a model, claiming that when perceivers assume an initial general sense of similarity to a target, they engage in greater projection and less stereotyping. Three studies featuring manipulations of similarity support this claim. Moreover, reaction time results shed light on the mechanisms underlying these effects. The proposed model gives a new view of the mind reader's tool kit and, more generally, raises questions about moderators of stereotyping and projection in social judgment.
\end{abstract}

We are all mind readers. Not the magical sort, but rather the most ordinary, casually and quickly intuiting what the people around us think, want, and feel. A friend delivers an unwanted birthday present to us, and yet we know she meant well. A new colleague gushes with ideas in front of the boss, and we see not just enthusiasm but his self-promoting motives. A potential romantic partner resists our initial overtures, but somehow we sense (whether rightly or not) that a spark of interest may yet be kindled. At least since Heider's (1958) pioneering work on folk concepts such as "want" and "try," social psychologists have known that inferring mental states-reading minds-comes naturally, if somewhat imperfectly, to most adults and drives much of impression formation (e.g., Jones \& Davis, 1965; Read, Jones, \& Miller, 1990; Reeder, Kumar, Hesson-McInnis, \& Trafimow, 2002; Trope, 1989); causal explanation (e.g., Kruglanski, 1975; Malle, 2001; Sutton \& McClure, 2001); judgments of responsibility, praise, and blame (e.g., Shaver, 1985; Weiner, 1995); and social meaning (e.g., Bruner, 1990).

Although mental state inferences have been implicated in these and other important domains, models of how people ascribe these invisible properties to those around them remain fragmented. Various accounts in social psychology and elsewhere have isolated different tools, showing that perceivers, by turns, scrutinize overt behaviors, project their own mental states onto others, and rely on

This research was supported in part by a National Science Foundation Graduate Research Fellowship and the Columbia University Center for the Decision Sciences. Parts of this article are based on my doctoral dissertation at the University of California (UC), Berkeley. I thank Alison Gopnik, Robert MacCoun, Michael Morris, and Kaiping Peng for their thoughtful advice and generous help. This research has benefited greatly from support and comments by Carol Dweck, Blair Jarvis, Eric Knowles, Brian Lickel, Bertram Malle, Stephen Read, Amy Sanidas, Steve Stroessner, the community of scholars at the Institute for Personality and Social Research at UC Berkeley, and members of the Columbia University Social Psychology Network.

Correspondence concerning this article should be addressed to Daniel R. Ames, Columbia Business School, Columbia University, 707 Uris Hall, 3022 Broadway, New York, NY 10027. E-mail: da358@columbia.edu stereotypes (see Ames, in press-a). In this article, I begin with the assumption that people rely on all these routes at different times, and I explore what conditions affect the use of these different inferential strategies. The result is a sketch of the everyday mind reader's tool kit, and this account offers new insights for models of social judgment, including moderators of stereotyping and projection and a new portrait of sources of accuracy and distortion.

\section{Strategies for Mental State Inference}

Developmental psychologists have shown that infants enter the world ready to parse and scrutinize one another's behavior in terms of underlying intentions (e.g., Gopnik \& Meltzoff, 1997; Wellman, 1990). By the time people are adults, they have become experts in adopting such an "intentional stance" toward one another's acts (Dennett, 1987), reading unseen goals into arcs of ordinary behavior (e.g., Newtson, 1973) and performing fluid if fallible covariation across episodes of action to intuit a person's intentions (Jones \& Davis, 1965; Kammrath, Mendoza-Denton, \& Mischel, 2004; Kelley, 1973).

When behaviors are ambiguous, however, perceivers turn to other tools. For instance, the intent behind an apparent shove-was it hostile or playful? - may be determined by the perceiver's stereotype about the actor's race (Sagar \& Schofield, 1980). Even the anger assumed to underlie an ambiguous display of facial affect may hinge on stereotypes and the implicit prejudice of the perceiver (Hugenberg \& Bodenhausen, 2003). Aside from stereotyping, perceivers often demonstrate a projective impulse, assuming others think, want, and feel what they themselves think, want, and feel. Social psychological work on false consensus and social projection has revealed sweeping evidence that people commonly assume, often to an unwarranted degree, that their attitudes are shared by others (Krueger, 2000; Ross, Greene, \& House, 1977). Elsewhere, some cognitive scientists and philosophers have argued that a process of simulation and projection may account for much of people's ability to read minds (e.g., Goldman, 2001).

What, then, governs which inferential tool will be applied in a given situation? To narrow the question, let us focus on cases in which behavior is ambiguous: What governs when perceivers 
stereotype or project when reading minds? And do these strategies function as something like alternative inferential routes with the potential to displace one another? These important questions remain largely unanswered, but provocative hints can be found in recent work. For instance, Kunda and colleagues (Kunda, Davies, Adams, \& Spencer, 2002; Kunda \& Spencer, 2003) have shown that stereotype activation declines over the course of exposure to a target but that stereotypes may be reactivated on encountering a disagreement with the target. Elsewhere, Galinsky and colleagues (e.g., Galinsky \& Moskowitz, 2000) have found that perspective taking decreases stereotype accessibility and use, and Davis, Conklin, Smith, and Luce (1996) have argued that perspective taking can increase the overlap in representations of the self and others. Taken together, these streams of work suggest that a sense of dissimilarity (such as that provoked by the disagreements in the research of Kunda et al., 2002, and Kunda \& Spencer, 2003) may tip perceivers toward stereotyping, whereas a sense of similarity (which may be evoked by perspective taking) might draw perceivers away from stereotyping and toward projection. Yet these programs of research have not focused on mental state inferences, nor have they overtly argued that projection and stereotyping function as something like alternatives for one another. The present article brings these ideas together and tests them directly.

\section{The Proposed Model}

I suggest that when a target's behavior is ambiguous, perceivers shift between stereotyping and projection as mind-reading strategies. Specifically, when perceivers see themselves as initially more similar to a target, they will rely more heavily on projection and less heavily on stereotyping than when they see themselves as less similar. In short, I claim that perceived similarity plays a moderating role in inferential strategies. It is worth stressing that this effect is expected to revolve around subjective initial perceptions of general similarity, which are susceptible to distortions and may be founded on cues with questionable validity.

Why should perceived similarity have these moderating effects on projection and stereotyping? The self and stereotypes are two basic templates for understanding a target's unseen mental states. ${ }^{1}$ Both self and stereotype representations may be readily accessed and easily applied, conserving the perceiver's cognitive effort (cf. Gilbert \& Hixon, 1991). However, the perceiver's pursuit of ease may also be tempered in part by a striving for accuracy: When she senses that one template may not fit, she may switch to the other. An initial sense of general similarity may thus regulate the use of these templates, even though such judgments of similarity may be fallible. For instance, perceivers may overgeneralize similarity or dissimilarity from isolated cues. Accordingly, when I find a new acquaintance shares my love for an obscure comedian, I may extend myself as a template and assume he also shares my political views. Alternately, when I find a new colleague hates my favorite movie, I may abandon myself as a template and turn instead to a stereotype that may apply to her (e.g., an introverted, intelligent librarian). Whether valid or not, seemingly small cues could assume considerable importance by affecting a generalized sense of similarity that plays a function in regulating the application of stereotyping and projection.

What is at stake in the current work? If these proposed claims are validated, they would improve on existing models of stereo- typing and projection in being able to account for when those inferential strategies are employed (or displaced) as mind-reading tools. More generally, such results might raise questions for the broader stereotyping and projection literatures. A number of popular models of stereotyping stress the boundaries of stereotyping, but cast individuation as the predominant alternative (e.g., Brewer, 1988; Fiske \& Neuberg, 1990). Thus, the inferential alternative to stereotyping is often described as effortfully dealing with targets as distinct individuals. The current approach introduces another, seemingly low-effort alternative inferential strategy: projection. Meanwhile, models of false consensus describe in-group/outgroup distinctions as a boundary of projection (e.g., Clement \& Krueger, 2002), and models of naive realism suggest that maturity may curb knee-jerk assumptions of shared attitudes (e.g., Ross \& Ward, 1996). Such models do not describe a clear role for stereotyping as an alternative strategy that might supplant projection.

In addition, if the proposed model is borne out, it should attract attention to the matter of perceived self-other similarity. If such a sense of similarity has the important moderating role claimed for it, its own sources and nature would demand to be better understood. Further, this model has the potential to offer new portraits of accuracy and distortion in social judgment, allowing a more precise description of what goes wrong when people misread minds. I turn next to the research and evidence and then return to these and other issues in the article's conclusion.

\section{The Present Research}

The three studies reported here tested a prediction about the sources of mental state inferences: Higher levels of perceived general similarity to a target were expected to be associated with greater projection and less stereotyping. In Study 1, participants reviewed several scenes of behavior and made inferences about targets' mental states as well as their own likely mental states in such situations and those of typical members of groups to which the targets belonged (e.g., a fraternity member). Similarity was indirectly manipulated by altering target attributes, allowing a test of whether manipulated and perceived similarity yielded greater projection and less stereotyping. In Study 2, participants viewed a scene featuring a target's ambiguous behavior. In this case, similarity was directly manipulated for each participant, depending on his or her own idiosyncratic attributes. Target stereotype was also manipulated. This again allowed a test of whether perceived similarity yielded greater projection and less stereotyping as well as a test of whether these effects emerged for varying stereotype content. In Study 3, reaction time measures were used to examine inferential processes. Participants viewed a scene featuring a target's ambiguous behavior; perceived similarity to the target was manipulated. Response times for target, self, and stereotype questions were recorded, allowing tests of projection and stereotyping effects.

\footnotetext{
${ }^{1}$ The proposed model attempts to describe the use of several major inferential tools but does not present an exhaustive inventory of mindreading strategies. Other tools include using situational information to disambiguate behaviors (e.g., Reeder et al., 2002) and using third-party acquaintances as analogies (e.g., Chen, 2001). See Ames (in press-a) for an overview of inferential strategies.
} 


\section{Study 1}

Does a medical school student helping her professor simply want to be of assistance or is she actually hoping for a better grade? Does a fraternity member flirting with an attractive woman at a party hope to establish a meaningful relationship, or is he more interested in sexual conquest? Does a lawyer who prematurely reveals his work team's breakthrough ideas to his boss actually care about his colleagues or is he just looking to get ahead for himself? Participants in Study 1 were asked to read the minds of such medical school students, fraternity members, and lawyers. Specific attributes of the targets were varied as an indirect manipulation of similarity. For example, in one condition, the fraternity member was described as preferring hip-hop music to hard rock music; in another condition, he was described as preferring rock to hip-hop. These attributes were selected for being only moderately prevalent in the participant population-that is, some participants would share any given attribute with the targets whereas others would not (e.g., some would prefer hip-hop whereas others would prefer rock). The attributes were also chosen for being orthogonal to the mental state inferences at hand (e.g., whether the fraternity member actually cared about his partner's feelings in the long run).

Participants indicated their own corresponding attributes (e.g., own liking for hip-hop), and it was assumed that matches between self and target on these attributes would lead to higher levels of perceived similarity. Participants also recorded their mental state inferences about the targets as well as their own likely mental states in such situations and the likely mental states of relevant group members (e.g., the typical fraternity member). These judgments allowed a test of whether perceived similarity would increase projection and decrease stereotyping. It was expected that this would emerge across all scenarios, regardless of the content of the similarity cues (e.g., whether or not the target preferred hiphop) or the order of the dependent measures. It was also assumed that projection and stereotyping would be negatively related to one another.

\section{Method}

Participants. Seventy-four university students (43 men, 31 women) participated in Study 1 as part of a paid research session. Mean age was 20.9 years. Thirty-five participants identified themselves as Caucasian/ White, 24 as Asian American/Asian, 9 as African American/Black, and 4 as Latino/a or Hispanic, with the remaining 2 indicating "Other."

Materials. Materials included a multipart pencil-and-paper survey. The initial section of the survey gauged perceptions of similarity to several groups, including medical school students, fraternity members, and lawyers. Participants rated agreement with items (including filler items as well as the three items of interest: "I'm similar to most medical school students," "I'm similar to most lawyers," and "I'm similar to most fraternity members") on a 6-point scale ranging from 1 (Strongly disagree) to 6 (Strongly agree). Participants also indicated their gender, age, and ethnicity.

Participants then responded to six items that they were told would be relevant later in the survey. These items included, "Do you enjoy the television show South Park?", "Do you enjoy watching professional sports on television?", "Do you prefer hip-hop music to hard rock music?", "Do you enjoy snowboarding?", "Do you like the comedian Adam Sandler?", and "Do you support a ban on smoking in bars?" For each question, participants were asked to circle whichever one of two options ("Primarily Yes" or "Primarily No") best reflected their views. These questions were selected on the basis of pilot testing that revealed three things: First, that the participant population varied in responses to these items (consensus was between $25 \%$ and $75 \%$ ); second, that these cues were viewed as relevant to diagnosing one's own general similarity to another person; and third, that these cues in and of themselves were not directly predictive of the mental states and behaviors of the vignette characters, as described below.

Participants recorded impressions about three characters on the basis of vignettes. The first vignette featured a character named Alice. Participants in one cue version read the following:

Let's begin with Alice, a 28-year-old medical school student (she's studying to be a doctor). Alice loves the television show South Park-she has even bought some DVDs of the show. Alice doesn't really enjoy playing or watching sports and only very rarely watches sports on television.

Participants in the other cue version read, "Let's begin with Alice, a 28-year-old medical school student (she's studying to be a doctor). Alice says she can't really stand the television show South Park. Alice loves playing and watching sports and frequently watches sports on television."

Participants then indicated their similarity to Alice by rating agreement with the statement "I'm similar to Alice" on a 12-point scale ranging from 1 (Strongly disagree) to 12 (Strongly agree). In all conditions, participants next read the same description of a scene involving Alice:

Alice is walking across campus one day after classes and comes across a person crouching next to a bicycle. It's obvious that the chain on the bicycle has come off and the person is struggling to repair it. The chain is greasy and dirty and the person is getting messy but doesn't appear to be having any luck with it. Alice notices that the person is actually a professor in one of her most important classes. She pauses and stops and then goes over and begins helping. She finishes fixing the chain for the professor. The professor thanks her and Alice smiles and continues on her way.

After reading about the scene, participants rated Alice's mental states by rating agreement with items on a 12-point scale ranging from 1 (Strongly disagree) to 12 (Strongly agree). The eight items included, "Alice wanted to help any person in need," "Alice hoped she would get a better grade for helping," "Alice felt shy about interacting with the professor," "Alice was sad to see someone struggling," "Alice wanted to impress the professor to get a better grade," "Alice thought the professor was dumb for not being able to fix the bike alone," "Alice felt excited about a chance to be recognized by the professor," and "Alice cared more about being nice than getting a better grade."

Participants in the self-then-group order condition then rated the same items for themselves. The instructions noted, "What do you think you would have felt in this kind of situation?" Participants rated their own likely mental states by rating agreement with items on a 12-point scale ranging from 1 (Strongly disagree) to 12 (Strongly agree). The items were modified versions of the eight items described above (e.g., "I would have wanted to help any person in need," "I would have hoped I would get a better grade for helping"). Next, participants rated agreement on the same scale for medical school students. The instructions noted, "What do you think a typical medical school student would have felt in this situation?" The items were modified versions of the eight items described above (e.g., "They would have wanted to help any person in need," "They would have hoped they would get a better grade for helping").

Participants in the group-then-self order condition completed the same sets of items but completed the medical school student questions before the self questions.

The second vignette featured a character named Mark. Participants in one cue version read, "Mark is a 20-year-old fraternity member. Mark says he definitely prefers hard rock music to hip-hop (he doesn't own any 
hip-hop music). Mark loves snowboarding and goes as often as he can during the winter months." Participants in the other cue version read, "Mark is a 20-year-old fraternity member. Mark says he definitely prefers hip-hop to hard rock music (he doesn't own any rock music). Mark doesn't snowboard and says he has no interest in learning it."

Participants then indicated their similarity to Mark by rating agreement with the statement "I'm similar to Mark" on a 12-point scale ranging from 1 (Strongly disagree) to 12 (Strongly agree). In all conditions, participants next read the same description of a scene involving Mark:

At his fraternity's big annual party, Mark spots Kim dancing. They've been in a class together but have never really talked. Mark works his way through the crowd until he's dancing next to her. "You look great," he says over the music and smiles at her. She smiles back and they dance for a while longer. Suddenly, someone bumps into Mark and he bumps into Kim. She's startled and he says he's sorry. The song ends and Kim says, "I'm taking a break." Mark replies, "Why don't we go somewhere we can talk. I know a place." He reaches down and takes her hand and squeezes off into the crowd. As he passes his roommate who is dancing nearby, he flashes a big grin.

After reading about the scene, participants rated Mark's mental states by indicating agreement with items on a 12-point scale ranging from 1 (Strongly disagree) to 12 (Strongly agree). The eight items included "Mark believed he could seduce Kim that night," "Mark wanted to know more about Kim's personality and opinions," "Mark wanted to get Kim into bed (fooling around with him) as soon as possible," "Mark didn't really care about Kim's feelings in the long run," "Mark was thrilled about the possibility of making a sexual conquest," "Mark was nervous about whether or not Kim would like him," "Mark believed Kim was an interesting person worth knowing better," and "Mark wanted Kim to like him as a person."

Participants in the self-then-group order condition then rated the same items for themselves. The instructions noted, "What do you think you would have felt in that kind of situation at a party-with an attractive person you don't know very well?" Participants rated their own likely mental states by rating agreement with items on a 12-point scale ranging from 1 (Strongly disagree) to 12 (Strongly agree). The items were modified versions of the eight items described above (e.g., "I would have believed I could seduce that person that night," "I would have wanted to know more about that person's personality and opinions"). Next, participants rated agreement on the same scale for fraternity members. The instructions noted, "What do you think a typical fraternity member would have felt in this situation?" The items were modified versions of the eight items described above (e.g., "They would have believed they could seduce that person that night," "They would have wanted to know more about that person's personality and opinions"). Participants in the group-then-self order condition completed the same sets of items but completed the fraternity member questions before the self questions.

The third vignette featured a character named Steve. Participants in one cue version read, "Steve is a lawyer in his late-20s. Steve loves Adam Sandler and makes a point of seeing any new movie featuring him. Steve also strongly supports bans on smoking in bars." Participants in the other cue version read, "Steve is a lawyer in his late-20s. Steve doesn't like Adam Sandler and makes a point of avoiding any new movie featuring him. Steve also strongly opposes bans on smoking in bars."

Participants then indicated their similarity to Steve by rating agreement with the statement "I'm similar to Steve" on a 12-point scale ranging from 1 (Strongly disagree) to 12 (Strongly agree). In all conditions, participants next read the same description of a scene involving Steve:

Steve has been working with two other people in his law office on a project. They all worked long hours on a difficult problem with a contract law case and each one contributed creative ideas that were part of the final solution. The whole team was looking forward to making a presentation to the firm about their new ideas. Before the day of the presentation, Steve was walking through the office and saw the head partner of the firm. The partner came over and exchanged greetings. He asked what was new and Steve told him briefly about the team's solution to the problem. The partner was extremely impressed and continued pressing for more information. The partner loved the solution and said that Steve would be in line for a promotion.

After reading about the scene, participants rated Steve's mental states by rating agreement with items on a 12-point scale ranging from 1 (Strongly disagree) to 12 (Strongly agree). The eight items included the following: "Steve wanted to share credit with the others," "Steve was pleased about this chance to talk with the boss," "Steve believed this was a great opportunity to advance his career," "Steve would have been willing to sacrifice his own interests for the sake of his teammates," "Steve didn't really care what happened to his teammates," "Steve wanted to move ahead in the company more than anything else," "Steve believed his colleagues would also be recognized for their work," and "Steve felt bad about explaining the solution without his teammates there."

Participants in the self-then-group order condition then rated the same items for themselves. The instructions noted, "What would you have felt in this situation?" Participants rated their own likely mental states by rating agreement with items on a 12-point scale ranging from 1 (Strongly disagree) to 12 (Strongly agree). The items were modified versions of the eight items described above (e.g., "I would want to share credit with the others," "I would be pleased about this chance to talk with the boss"). Next, participants rated agreement on the same scale for fraternity members. The instructions noted, "What do you think a typical lawyer would have felt in this situation?" The items were modified versions of the eight items described above (e.g., "They would want to share credit with the others," "They would be pleased about this chance to talk with the boss"). Participants in the group-then-self order condition completed the same sets of items but completed the lawyer questions before the self questions.

Procedure. Participants were recruited to take part in research sessions on impression formation. After arriving and completing informed consent materials, participants were randomly assigned to an experimental condition and given a hard-copy survey containing materials as described above. After completing the materials, participants were debriefed and paid.

\section{Results}

The results are discussed in four parts: (a) a description of the stereotyping and projection constructs; (b) tests to confirm that collapsing across the three scenes is warranted; (c) tests of the predicted effects of perceived similarity on stereotyping and projection; and (d) additional analyses of variable order, cue version, and other effects.

Constructs. Projection and stereotyping constructs were computed using each participant's responses across each vignette's eight mental state items for the target, themselves, and the relevant stereotype (see Figure 1 for an illustration). For each scenario for each participant, a multiple regression was computed, predicting target responses with self responses and group responses. The resulting standardized beta weights were then used as measures of projection (the self response beta) and stereotyping (the group response beta). Thus, the more a participant's own responses predicted the target response, the higher his or her measure of projection was. The more a participant's group responses predicted the target response, the higher their measure of stereotyping was.

Collapsing across scenes. It was expected that the predicted effects (projection increasing with perceived similarity, stereotyping decreasing with perceived similarity) would not vary by scene. 
If tests of these interactions were not significant, collapsing across scene would be warranted. This was indeed the case. In analysis of variance (ANOVA) models predicting projection and stereotyping with low (0) and high (2) self-target similarity cue matches (i.e., participant responses to both the similarity cue items were inconsistent with or consistent with target attributes), scene showed main effects on projection, $F(2,104)=5.10, p=.01$, and stereotyping, $F(2,104)=3.06, p=.05$, but no significant interaction effects $(F=0.39, p=.68$ and $F=1.68, p=.19$, respectively). The same pattern of results emerged using a tertiary split on perceived similarity rather than the cue matches: Scene had main effects on projection and stereotyping, $F(2,140)=6.97$, $p<.01$, and $F(2,140)=6.46, p<.01$, respectively, but did not significantly interact with similarity, $F(2,140)=0.08, p=.93$, and $F(2,140)=1.29, p=.28$. These scene main effects were due in part to lower average levels of projection in the fraternity party scene $(M=.06)$ compared with the medical student $(M=.35)$ and lawyer $(M=.39)$ scenes and higher levels of stereotyping in the fraternity scene $(M=.77)$ compared with the medical student $(M=.48)$ and lawyer $(M=.51)$ scenes. In sum, the absence of interaction effects between scene and similarity on the dependent variables indicates that collapsing across scene was acceptable in testing the predicted effects of similarity.

Effects of similarity on projection and stereotyping. The central prediction for Study 1 was that the number of matched cues between participants and targets (e.g., shared liking for hip-hop music) would positively predict projection and negatively predict stereotyping. This was confirmed. Collapsing across scenario, variable order, and cue version, the sum of matched cues (selftarget agreement on the yes-no questions, ranging from 0 through 2) correlated positively with projection $(r=.17, p=.02, n=206)$ and negatively with stereotyping $(r=-.12, p=.09)$. A repeatedmeasures ANOVA confirmed that this interaction was significant: The contrast between no matched similarity cues and two matched similarity cues significantly predicted the two-level factor of projection and stereotyping, $F(1,103)=4.66, p=.03$ (see Figure 2).

The predicted effects emerged even more clearly for ratings of perceived similarity: These ratings correlated positively with pro-

\begin{tabular}{|c|c|c|c|}
\hline \multirow[b]{2}{*}{ Mental states } & \multicolumn{3}{|c|}{ 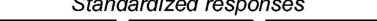 } \\
\hline & For Alice & For self & For group \\
\hline ... wanted to help any person in need & 0.00 & 0.57 & -0.13 \\
\hline ... hoped would get a better grade & 0.98 & 0.57 & 0.91 \\
\hline ... felt shy about interacting & 0.25 & -1.62 & -0.39 \\
\hline$\ldots$ was sad to see someone struggling & -0.74 & 0.37 & 0.39 \\
\hline ... wanted to impress the professor & 0.98 & 0.57 & 0.91 \\
\hline ... thought the professor was dumb & -1.72 & -1.62 & -1.95 \\
\hline ... felt excited about chance to be recognized & 0.98 & 0.57 & 0.91 \\
\hline ....cared more about being nice than grade & $\mid \begin{array}{l}\boldsymbol{\beta}= \\
\text { (ho } \\
\text { pre }\end{array}$ & $\begin{array}{l}0.57 \\
\text { rojection } \\
\text { ell self respons } \\
\text { d target respo }\end{array}$ & $\mid$ \\
\hline & & $\begin{array}{l}3=\text { stereo } \\
\text { how well gro } \\
\text { redicted targ }\end{array}$ & $\begin{array}{l}\text { jing } \\
\text { esponses } \\
\text { esponses) }\end{array}$ \\
\hline
\end{tabular}

Figure 1. Within-participant, across-item computation of projection and stereotyping constructs.

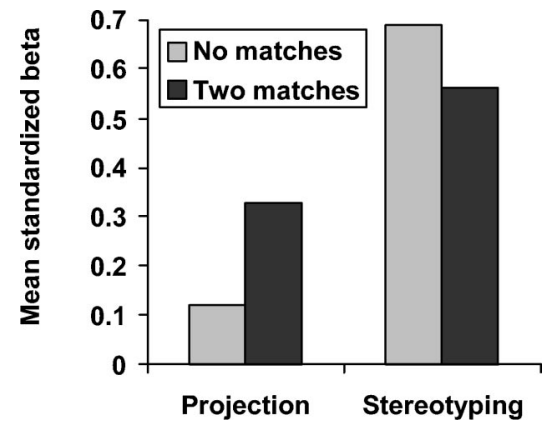

Figure 2. Projection and stereotyping as a function of self-other similarity cue matches, Study 1.

jection $(r=.23, p<.01, n=206)$ and negatively with stereotyping $(r=-.18, p<.01)$. This general pattern of results emerged in the individual scenes as well. ${ }^{2}$ These findings are consistent with the proposed model, which would suggest that the cue matches would have their effect by affecting perceptions of similarity. Indeed, perceived similarity ratings were strongly and positively correlated with cue matches $(r=.51, p<.01)$ and were also positively correlated with participant's initial ratings of similarity to the relevant group (medical school students, fraternity members, lawyers; $r=.31, p<.01$ ). In a combined regression model, both similarity cue matches $(\beta=.49, p<.01)$ and perceived similarity to group $(\beta=.27, p<.01)$ were simultaneously predictive of perceived similarity to target. As expected, the perceived similarity measure mediated the effects of cue matches on both projection and stereotyping. ${ }^{3}$ In sum, these analyses confirm the predicted effects: similarity cue matches affected perceived similarity, and higher levels of perceived similarity led to higher levels of projection and lower levels of stereotyping.

Other analyses. To test whether cue version (e.g., whether Alice was described as enjoying or not enjoying watching sports) mattered to the predicted effects, ANOVA models were conducted predicting projection and stereotyping with cue matches ( 0 vs. 2), scene, and cue version. If the effect of similarity on projection and stereotyping depended on the version of the cue (e.g., enjoying vs. not enjoying sports), then the Cue Match $\times$ Version interactions would be significant. This was not the case for either projection, $F(2,104)=0.40, p=.67$, or stereotyping, $F(2,104)=1.86, p=$ .16. If this emerged only for selected scenes, the Cue Match $\times$

\footnotetext{
${ }^{2}$ Those in the top third of perceived similarity showed higher levels of projection than those in the bottom third ( $>6$ vs. $<4$ on the 12-point scale; .40 vs. .30 for the medical student scene, .15 vs. -.01 for the fraternity scene, and .44 vs. .28 for the law office scene). Those in the top third of perceived similarity showed lower levels of stereotyping than those in the bottom third (.46 vs. .52 for the medical student scene and .43 vs. .66 for the law office scene; however, the fraternity scene did not show the expected stereotyping pattern, .79 vs. .75).

${ }^{3}$ In a combined regression model predicting projection with both cue matches and perceived similarity, cue matches were not significantly predictive $(\beta=.07, p=.38)$ whereas perceived similarity was $(\beta=.20$, $p=.01)$. In a combined regression model predicting stereotyping with both cue matches and perceived similarity, cue matches were not significantly predictive $(\beta=-.04, p=.66)$ whereas perceived similarity was $(\beta=$ $-.16, p=.04)$.
} 
Version $\times$ Scene interactions would be significant. Again, this was not the case for either projection, $F(2,104)=0.34, p=.71$, or stereotyping, $F(2,104)=1.04, p=.36$. It is also worth noting that participants' own responses to the cues displayed the expected levels of variance (47\% said "yes" to the South Park question, 50\% to the sports question, $54 \%$ to the hip-hop music question, $70 \%$ to the snowboarding question, $34 \%$ to the Adam Sandler question, and $38 \%$ to the smoking ban question). In sum, as expected, cue matches and perceived similarity appeared to drive the projection and stereotyping effects, not something specific about the content of the cues.

To test whether dependent variable order (i.e., whether answering self items before group items rather than vice versa) mattered to the predicted effects, ANOVA models were conducted predicting projection and stereotyping with cue matches (0 vs. 2) and dependent variable order. If the effect of similarity on projection and stereotyping depended on order of the dependent variables, then the Cue Match $\times$ Order interactions would be significant. This was not the case for either projection, $F(1,104)=0.08, p=$ .78 , or stereotyping, $F(1,104)=1.01, p=.32$. Further, order did not have a main effect on either projection, $F(1,104)=0.61, p=$ .44 , or stereotyping, $F(1,104)=0.19, p=.67$. In sum, as expected, dependent variable order did not appear to affect the predicted effects.

The proposed model suggests that projection and stereotyping may be traded off and serve as alternatives for one another. This is implicit in the above results, with projection being positively associated with similarity whereas stereotyping was negatively associated with similarity. A direct correlation test validated this: The standardized beta weight measure of projection correlated negatively with the standardized beta weight measure of stereotyping $(r=-.69, p<.01)$. Within-participant analyses provided additional tentative evidence. Although statistical power was limited, such analyses were at least directionally consistent with the notion that perceivers shifted between projection and stereotyping and were guided in doing so by perceived similarity. ${ }^{4}$

Finally, potential effects of participant sex were considered. The proposed model was expected to apply regardless of participant sex, and this appeared to be the case. In multiple regression models predicting projection and stereotyping with similarity ratings, sex, and an interaction of Similarity Rating $\times$ Sex, only similarity ratings emerged as significant $(p s<.05)$. Main effects of sex on projection and stereotyping were not significant $(p s>.22)$ nor were interactions of sex and similarity ratings $(p s>.17)$. Additional analyses showed that sex had no significant effects on similarity ratings overall or at the scene level, even though one scene featured a female target, whereas the other two featured males.

\section{Discussion}

The results of Study 1 support the proposed model. When participants perceived themselves as similar to a target, they engaged in higher levels of projection and lower levels of stereotyping in mental state inferences than when they perceived themselves as dissimilar. These effects emerged across three scenes featuring different similarity cues (e.g., liking for South Park, enjoyment of snowboarding), different behavioral contexts (e.g., providing help to authority figures, romantic courtship and seduction), and differ- ent stereotypes (e.g., fraternity members, lawyers). The effects emerged regardless of dependent variable order or of the actual content of the similarity cues (e.g., liking vs. disliking South Park). Further, not only were projection and stereotyping related to perceived similarity in opposite ways, but these constructs were also negatively related to one another, suggesting that they may function as alternative inferential strategies.

\section{Study 2}

The results of Study 1 are consistent with the notion that perceived similarity increases projection and decreases stereotyping in mental state inference. These results emerged for multiple scenarios featuring different stereotypes. However, Study 1 featured an indirect manipulation of perceived similarity by manipulating attributes assigned to targets that varied in the participant population (e.g., liking for hip-hop music) and then capitalizing on matches or mismatches. Study 2 directly manipulated similarity through an interactive computer-based design such that participants were randomly assigned to either a similarity or dissimilarity condition, and target attributes were then dynamically generated on the basis of each participant's own attributes.

Further, manipulating the relevant stereotype-including stereotypes with both positive and negative content-while holding the scenario constant would clarify that use of stereotypes is not necessarily contingent on stereotype content. Accordingly, in Study 2, targets were described as belonging to one of three groups with varying stereotypes: master of business administration (MBA) students, master of social work (MSW) students, or master of library science (MLS) students. These three groups were selected on the basis of pilot testing that revealed that the groups were seen as varying in agreeableness and extraversion, with MBA students high in extraversion and low in agreeableness, MSW students as moderate in extraversion and high in agreeableness, and MLS students as low to moderate in extraversion and moderate in agreeableness. The central prediction was that perceivers sensing dissimilarity to a target would rely more heavily on stereotype content in mental state inferences (regardless of whether those stereotypes were positive, negative, or nonevaluative) whereas perceivers sensing similarity would rely more heavily on projection. By using multiple group stereotypes, Study 2 incorporated stereotype content that varied in both highly evaluative (i.e., agreeableness) and less evaluative (i.e., extraversion) dimensions.

\footnotetext{
${ }^{4}$ It was possible to correlate perceived similarity with projection and stereotyping for each participant across the three scenes, though a number of cases were excluded because of no variance in perceived similarity or missing values for one or more scenes (i.e., incalculable betas), yielding $n=46$. Given that the correlations featured only three pairs of values, the results feature considerable levels of variance, yet they are suggestive. The mean Fisherized correlation between similarity and projection was positive $(M=.60, S D=2.88)$, whereas the mean Fisherized correlation between similarity and stereotyping was negative $(M=-.35, S D=4.44)$. The mean Fisherized correlation between projection and stereotyping was also negative $(M=-.65, S D=4.14)$. None of these values differ significantly from zero, but they are directionally consistent with the notion that perceivers shifted between projection and stereotyping on the basis of perceived similarity.
} 


\section{Method}

Participants. One hundred two university students (53 men, 49 women) participated as part of a paid research session (participants were paid \$7). Mean age was 21.7 years.

Materials. Participants recorded impressions of a target after being randomly assigned to either a similarity or a dissimilarity condition and to one of three possible target groups (MBA, MSW, or MLS students). Through computer-based materials, participants were asked to imagine being paired up with someone as part of a personality assessment workshop and then solving challenging puzzles together. Participants indicated how they would feel in such a situation by rating agreement with eight items on a scale ranging from 1 (Not at all) to 5 (Very much). Four items were concerned with agreeableness ("I would want my partner to have fun and feel comfortable," "I would like helping my partner," "I would be more interested in performing well than being nice" [reversed], and "I would feel happy about cooperating with my partner"), whereas the remaining four were concerned with extraversion ("I would want to listen more than talk," "I would like publicly sharing my own ideas and opinions," "I would like it when my partner controlled the conversation" [reversed], and "I would feel anxious about meeting someone new" [reversed]). The agreeableness and extraversion items were intermingled.

Participants in the MBA target condition were then told that

people would react to such a "problem-solving with a stranger" situation in different ways. Now, we want your view on how you think Master's of Business Administration students (also called MBAs or business school students) would feel. We realize you don't have a lot of information to go on, but tell us your views as best you can.

Participants in the MSW and MLS conditions read instructions relevant to their target group. Participants then rated modified versions of the mental state items noted above (e.g., "They would want their partner to have fun and feel comfortable") on the same 5-point scale.

As part of the similarity manipulation, participants then responded to three yes-no questions ("Do you generally like actor/comedian Adam Sandler?"; "Do you usually enjoy watching sports?"; and "Do you think your friends would describe you as quite artistic and creative?"). Participants were then told about the target, named Brian. Participants in the similarity condition were told that Brian shared their responses on all three items. For example, a participant in the similarity condition with an MBA target who responded "yes" to all three items was shown the following:

Brian is an MBA student at Columbia Business School. Recently, he participated in an assessment program in which people were paired up with a stranger and then observed in a number of tasks. Brian responded similarly to you on a number of questions: he likes Adam Sandler and enjoys watching sports. He also said his friends would describe him as artistic and creative. While you and Brian may have some differences, it appears you have at least a few important things in common.

Participants in the dissimilarity condition were told that the target did not share their responses to any of the questions. After reading this brief description of Brian, participants indicated their initial sense of similarity by rating agreement with the statement, "I believe I have a lot in common with Brian" on a scale ranging from 1 (Not at all) to 5 (Definitely).

Participants were then shown an episode of approximately $30 \mathrm{~s}$ featuring Brian and another character, David. The clip featured two male actors working on a logic puzzle similar to those found in standardized tests (in this case, identifying what kinds of fish a seafood restaurant could serve on a given night in light of various restrictions such as "Halibut is served on three days each week, but never on Friday"). Participants were told, "Don't worry about following the problem itself, just focus on Brian throughout the episode."
After the episode was completed, participants answered questions about Brian's mental states. The eight mental state items were modifications of the agreeableness and extraversion items noted above (e.g., "He wanted his partner to have fun and feel comfortable").

Procedure. Participants were recruited to take part in paid research sessions on social judgments. After arriving and completing informed consent materials, participants were randomly assigned to an experimental condition and seated at individual computer workstations, where they completed computer-based survey materials as described above. After completing the materials, participants were debriefed and paid.

\section{Results}

Manipulation checks. As expected, participants in the similarity condition showed a higher mean initial similarity rating versus those in the dissimilarity condition (2.4 vs. 2.1$), t(98)=1.7, p=$ .09. The target groups revealed different stereotypes as expected. A one-way ANOVA using group to predict ratings of agreeableness and extraversion mental states (reversed as indicated above and then averaged) showed significant effects, $F(2,97)=36.2$, and $F(2,97)=26.4$, respectively, both $p$ s $<.01$. MSW students were seen as highest in agreeableness ( 4.3 vs. 3.8 for MLS students and 2.9 for MBA students), whereas MBA students were seen as highest in extraversion (4.2 vs. 3.3 for MSW students and 3.2 for MLS students).

Participants' own responses to the cue questions revealed expected levels of variance in the participant population: $66 \%$ of participants indicated liking Adam Sandler, 48\% indicated liking sports, and $57 \%$ indicating having artistic abilities.

Constructs. As in Study 1, projection and stereotyping measures were created by computing within-participant multiple regressions across the mental state items (see Figure 1), predicting each participant's ratings of Brian's mental states with the participant's self-ratings and the participant's ratings of the relevant group (MBA, MSW, or MLS students). The standardized beta coefficient for self ratings was used as a measure of projection, whereas the standardized beta coefficient for group ratings was used as a measure of stereotyping.

Effects of similarity on projection and stereotyping. A repeated-measures ANOVA revealed a significant interaction of the similarity manipulation on the projection and stereotyping measures, $F(1,95)=8.6, p<.01$. As shown in Figure 3, focused tests were consistent with the central prediction for Study 2: Projection was higher in the similarity than the dissimilarity condition (.42 vs. .08), $t(95)=3.3, p<.01$, whereas stereotyping was

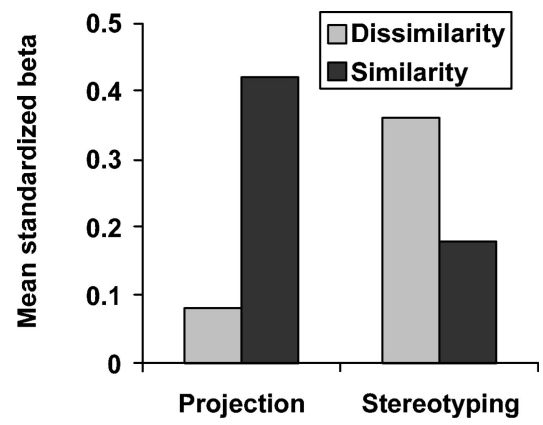

Figure 3. Projection and stereotyping as a function of similarity condition, Study 2. 
lower in the similarity condition than the dissimilarity condition (.18 vs. .36), $t(95)=-1.8, p=.07$. The projection and stereotyping measures were significantly negatively correlated $(r=$ $-.55, p<.01)$.

The proposed model suggests that the effect of similarity on projection and stereotyping would emerge regardless of stereotype valence and content. Accordingly, tests of the interaction between similarity and group (MBA, MSW, MLS) on projection and stereotyping were not significant, $F(2,96)=1.05, p=.35$, and $F(2$, $96)=.72, p=.49$, respectively. Within-group analyses showed directional findings parallel to those above, with higher projection in the similarity versus dissimilarity condition (.33 vs. -.18 for the MBA target, .56 vs. .39 for the MSW target, and .35 vs. .07 for the MLS target) and lower stereotyping in the similarity versus dissimilarity condition (.18 vs. .51 for the MBA target, .20 vs. .24 for the MSW target, and .16 vs. .30 for the MLS target).

Effects of cue content. It was expected that the cues used (liking for Adam Sandler, liking for sports, and artistic abilities) would not affect the similarity manipulation's impact on projection and stereotyping. This was confirmed: Target attributes (e.g., liking for sports) did not significantly affect the positive relationship between similarity and projection or the negative relationships between similarity and stereotyping. Further, there were no direct effects of the cues on ratings of agreeableness-related mental states ( $p$ s $=.32-.37$ ). However, the target's liking for Adam Sandler was positively linked with ratings of the target's extraversion-related mental states (i.e., Sandler fans were seen as more outgoing), $F$ (1, $100)=11.1, p<.01$. Nonetheless, the expected effects of similarity on projection and stereotyping emerged regardless of the target's liking for Adam Sandler; ANOVA models predicting projection and stereotyping did not show a significant interaction of Sandler liking with the similarity manipulation $(~ p s=.16-.82)$. The Sandler-liking cue was unrelated to agreeableness ratings, and the sport and art cues had no significant effect on agreeableness or extraversion ratings ( $p$ s $=.24-.54$ ). In sum, although one cue did appear to signal extraversion, none of the cue contents themselves affected the predicted positive relationship between similarity and projection or the predicted negative relationship between similarity and stereotyping.

\section{Discussion}

As with Study 1, results from Study 2 support the proposed model: Participants encouraged to believe they were similar to a target engaged in more projection and less stereotyping than those encouraged to believe they were different. These effects emerged regardless of stereotype content (MBA, MSW, or MLS) and emerged regardless of the similarity cue content (e.g., liking vs. disliking for sports). Finally, as in Study 1, projection and stereotyping were negatively related to one another.

\section{Study 3}

Taken together, Studies 1 and 2 support the idea that initial perceived similarity may increase the use of projection and decrease the use of stereotyping in mental state inference. These effects emerged across a range of positive and negative stereotypes and for various cues to similarity. However, the evidence from Studies 1 and 2 revolves around covariation in the reported con- tents of mental states (i.e., the extent to which inferred target mental states resembled self mental state responses or assumed stereotypic mental states). Study 3 sought more direct evidence of the underlying cognitive processes by using response time measures and a task facilitation approach (e.g., Klein, Loftus, Trafton, \& Fuhrman, 1992).

A brief description of the design is required to fully express the predictions. As in Study 2, perceived similarity to a target was manipulated, and participants then watched a brief video of a target, in this case described as an investment banker in a negotiation exercise. After the scene, participants responded to three versions of mental state questions: one version about the target (e.g., Michael wanted to win at all costs), one about themselves (e.g., I would have wanted to win at all costs), and one about their investment banker stereotype (e.g., most investment bankers would have wanted to win at all costs). The order of these questions was manipulated such that target questions were preceded by either stereotype or self questions (stereotype-target-self vs. selftarget-stereotype order), and reaction times were gathered.

To test for stereotyping and projection effects, Study 3 drew on Klein et al.'s (1992) task facilitation paradigm, which suggests that if information needed for a second inferential task is used in a prior task, the second task will be executed more quickly than if the prior task had not been recently completed. Thus, reaction times for a second task in light of a preceding one can shed light on whether the judgments rely on the same information. This paradigm allows a look at how self and stereotype information might be used in mind reading by altering whether self or stereotype judgments are recorded before target judgments. According to the proposed model, self responses (rather than stereotype responses) should best facilitate target responses when similarity is perceived, because projection suggests these tasks rely on the same information. Likewise, stereotype responses (rather than self responses) should best facilitate target responses when dissimilarity is perceived, because stereotyping suggests these tasks rely on the same information. (For a related argument in which group responses facilitate self responses, see Coats, Smith, Claypool \& Banner, 2000; Smith \& Henry, 1996.) In other words, when the initial response "fits" with perceived similarity (self responses under similarity, stereotype responses under dissimilarity), the subsequent response ought to be faster. Perceivers will use what is "top of mind" when it is consistent with their sense of similarity.

This prediction can be contrasted with an activation-only account in which perceivers capitalize on whatever construct is activated. In this view, self and stereotype initial responses would facilitate target responses equally, because perceivers would simply take the expedient route of applying whatever is most accessible rather than seeking a fit with perceived similarity. This view would predict no interaction of similarity and dependent variable order on target response times.

\section{Method}

Participants. Seventy-one university students (40 men, 31 women) participated as part of a paid research session (participants were paid \$8). Mean age was 22.5 years.

Materials. Participants were randomly assigned to two conditions: (a) similarity versus dissimilarity to a target person and (b) dependent variable order (either self-target-group or group-target-self). In brief, participants first received information about the similarity (or dissimilarity) to a target 
and then watched a brief video of the target interacting with another person. Participants then judged the target's mental states either after reporting their own likely mental states or after recording their assumed mental states for the target's group (in this case, investment bankers).

Participants completed materials on computer terminals running MediaLab v2004 (Empirisoft, 2004) experimental software. On beginning the experiment, participants read that they would be forming an impression of someone on the basis of a brief video clip. The instructions noted that in order to match the participant up with a clip, they would need to answer a few questions. Three dichotomous choices were then presented.

First, participants read a pair of jokes and indicated which one they preferred. The jokes were chosen from among top-rated entries in a recent online survey (LaughLab's World's Funniest Joke Project, n.d.) that sought to identify the "world's funniest joke." One featured a turtle:

A turtle was walking down an alley in New York when he was mugged by a gang of snails. A police detective came to investigate and asked the turtle if he could explain what happened. The turtle looked at the detective with a confused look on his face and replied "I don't know, it all happened so fast." (LaughLab's, n.d.)

The other joke featured a dog:

A dog went to a telegram office, took out a blank form and wrote: "Woof. Woof. Woof. Woof. Woof. Woof. Woof. Woof. Woof." The clerk examined the paper and politely told the dog: "There are only nine words here. You could send another 'Woof' for the same price." "But," the dog replied, "that wouldn't make any sense." (LaughLab's, n.d.)

Participants then indicated which of two pictures they preferred. The pictures were presented side by side as graphics with no indication of artist or title. One picture was "Improvisation 35" by Wassily Kandinsky (labeled "Painting A"); the other was "Blaue Nacht" by Paul Klee (labeled "Painting B").

The final dichotomous choice concerned a criminal case adapted from Pennington and Hastie (1992), the same case used by Kunda et al. (2002) in research on stereotype activation. The case (see the Appendix) outlined ambiguous evidence concerning a bank security guard who had been charged with embezzlement (e.g., a considerable sum of money was found in the defendant's apartment, but he also had a close friend as an alibi placing him elsewhere at the time of the crime). Participants indicated whether they thought the defendant was primarily innocent or primarily guilty.

After indicating innocence or guilt, participants read that they were being matched with a target. A cursor blinked on the screen while the message "Please wait for matching" appeared. Text then appeared along with a picture of a White male in his early 20 s in casual clothing (a still frame from the video described below). The text read "For today's session, you've been matched with Michael, an investment banker."

For participants in the similarity condition, the text continued "Michael appears to be similar to you in a few important ways. As part of a workshop he attended, he gave the following selections to the questions you answered earlier ..." Participants then clicked a button to continue to the next screen. The content on this screen depended on the participant's own responses. In the similarity condition, participants read that Michael had made the same choices they had. Someone who picked the dog joke, the Klee painting, and the innocence verdict, for instance, read that "Michael picked the dog joke. His comments: 'I thought this one was much funnier"' and that "Michael preferred Painting B. His comments: 'This one just seemed more artistic and beautiful"' (a graphic of Painting B accompanied this statement, visually reminding participants that the choice was the same as their own) and that "Michael indicated that he thought Graves was innocent. His comments: 'The evidence was very unclear to me, so I have to say he's innocent."”
Participants in the dissimilarity condition saw different versions of these two screens. In the first, the text read "Michael appears to be different from you in a few important ways. As part of a workshop he attended, he gave the following selections to the questions you answered earlier ..." Participants then clicked a button to continue to the next screen. The content on this screen depended on the participant's own responses. In the dissimilarity condition, participants read that Michael had made the opposite choices they had. Someone who picked the dog joke, the Klee painting, and innocence verdict, for instance, read that "Michael picked the turtle joke. His comments: 'I thought this one was much funnier"' and that "Michael preferred Painting A. His comments: 'This one just seemed more artistic and beautiful" (a graphic of Painting A accompanied this statement, visually reminding participants that the choice was the opposite of their own) and that "Michael indicated that he thought Graves was guilty. His comments: 'The evidence was pretty clear to me, so I have to say he's guilty.",

In all conditions, participants then indicated perceived similarity by answering the item, "What's your initial impression of how similar you are to Michael?" on a 7-point scale ranging from 1 (Very dissimilar) to 7 (Very similar).

Participants then read that they would see a short scene of Michael in a role-playing exercise from a negotiation workshop run for investment bankers. Participants were told Michael was in the role of someone selling a family business but that their goal was to form an impression of Michael rather than understand the issues of the negotiation itself. When ready, participants continued and watched the video, which lasted approximately $30 \mathrm{~s}$. The video featured a White male in his $20 \mathrm{~s}$ in a negotiation exercise, explaining his position to his negotiation partner. In reality, the actor was an organizational psychology graduate student who volunteered to be videotaped completing the exercise as part of a course on negotiation. The clip was chosen for its ambiguity: The male actor spoke for the entirety of the scene, which alternated between two camera angles, one focused on the actor and the other showing his female partner listening. He began by noting, "Ultimately we are looking to just exit the market, period. Just wipe the slate clean," and then described that he was open to the option of being bought out entirely or to continuing on as a consultant.

After the video was over, participants read the following instructions:

Now we'd like to get your impressions about Michael. We realize you might like to have more information about him, but give us your best judgment. Some of the questions that follow may be about you or other people. In those cases, imagine you or those people in the same kind of situation Michael was in-a role-playing negotiation exercise.

[Next screen.] The following questions will have two response options, like those shown below. If your response to a question is primarily NO, press the $1 \mathrm{key}$. If your response is primarily YES, press the 2 key. These are the only two options, so pick whichever one most closely matches your reaction. Now, to continue with the study, press the key corresponding to YES.

Participants continued by giving yes-no responses to 10 mental state items with three versions of each: one for Michael (e.g., "Michael wanted to win at all costs"), one for themselves (e.g., "I would have wanted to win at all costs"), and one for investment bankers (e.g., "Most investment bankers would have wanted to win at all costs"). The order of these items varied depending on two conditions. In the self-target-group condition, participants first responded to the self version of the mental state, then the target version, and finally the group version. This order was repeated within each mental state for all 10 mental states. In the group-target-self condition, this order was reversed. The MediaLab software recorded participant reaction times to all mental state item responses.

The 10 mental state stems included "wanted to win at all costs," "was comfortable talking to a stranger," "liked to fight for his share," "wanted to joke and have fun," "was eager to compete," "was excited," "was nervous about meeting someone new," "enjoyed debating and conflict," "wanted to 
be quick and efficient," and "wanted to avoid any tension." These items were chosen on the basis of their face validity relevance to the investment banker stereotype held by the participant population (i.e., eager, confident, competitive, assertive).

Procedure. Participants were recruited to take part in paid research sessions. After arriving and completing informed consent materials, participants were randomly assigned to an experimental condition and seated at a computer terminal that presented the materials described above via MediaLab experimental software. After completing the materials, participants were debriefed and paid.

\section{Results}

The similarity manipulation showed the expected effects on perceived similarity to the target (4.1 in the similarity condition vs. 2.6 in the dissimilarity condition), $t(69)=5.37, p<.01$. The remaining results are described in two sections: First, a replication of analyses from Studies 1 and 2, and second, analyses related to response times.

Effects of similarity on projection and stereotyping. Although Study 3 was designed primarily for exploration of reaction times, the target, self, and group responses lend themselves to test for replication of the results of Studies 1 and 2: whether similarity led to higher levels of projection and lower levels of stereotyping. Given the yes-no nature of the 10 mental state item responses, numbers of matched responses (e.g., when a participant responded "yes" for both target and self) were taken as measures of these constructs. The number of matches for target and self was used as a measure of projection (i.e., how many times a participant gave the same response for target and self), and the number of matches for target and group was used as a measure of stereotyping (i.e., how many times a participant gave the same response for target and investment banker).

These constructs revealed a pattern consistent with predictions and the results of Studies 1 and 2 (see Figure 4). Participants in the similarity condition showed greater projection than those in the dissimilarity condition ( 8.7 vs. 7.8$), t(69)=2.11, p=.04$, and less stereotyping than those in the dissimilarity condition (8.4 vs. 9.3), $t(69)=1.82, p=.07$. A repeated-measures ANOVA confirmed that the interaction was significant, $F(1,69)=9.44$, $p<.01$.

This pattern emerged regardless of dependent variable order

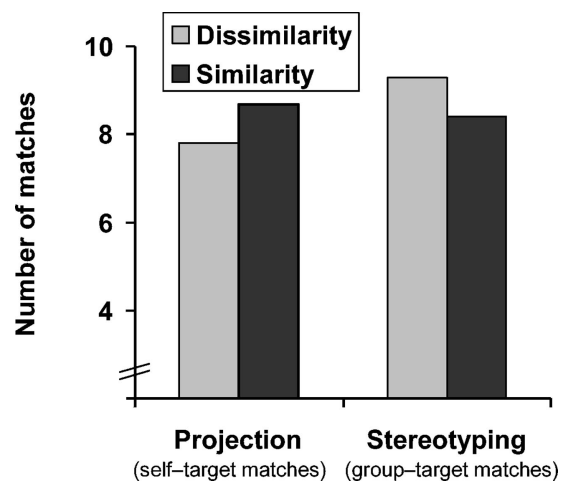

Figure 4. Projection and stereotyping as a function of similarity condition, Study 3. (i.e., the order variable did not significantly interact with similarity condition in predicting the Projection $\times$ Stereotyping interaction). Further, this pattern emerged regardless of the similarity or dissimilarity cues ascribed to the target (e.g., whether the target was described as preferring the turtle or the dog joke). It is worth noting that $51 \%$ of participants preferred the turtle joke, $59 \%$ preferred the Kandinsky painting, and $18 \%$ thought Graves was guilty.

Reaction times for target items. It was predicted that group responses would facilitate target responses in the dissimilarity condition more than the similarity condition whereas self responses would facilitate target responses in the similarity condition more than the dissimilarity condition. In other words, perceived similarity would govern whether participants applied the incidentally activated construct to the target. An alternative view would be that perceivers would capitalize on whatever construct was incidentally activated. In this view, both self and stereotype would be equally facilitating, so no interaction would emerge.

The results supported the proposed model's predictions. Using a lower cutoff for reaction times of $250 \mathrm{~ms}$ (based on pilot testing of minimal reading and comprehension times; below $250 \mathrm{~ms}$, values were excluded) and Windsorizing at 3 within-participant standard deviations above the mean (capping values at an average value of $6,500 \mathrm{~ms}$ ), a $2 \times 2$ ANOVA showed a significant interaction of similarity condition and variable order (self vs. group response before target response), $F(1,70)=7.26, p<.01$. As shown in Figure 5, the interaction took on the expected form. Target responses were faster for participants in the dissimilarity condition when they were preceded by group responses rather than self responses $(1,842.0 \mathrm{~ms}$ vs. $2,166.0 \mathrm{~ms}), t(32)=1.84, p=.07$. Alternately, target responses were faster for participants in the similarity condition when they were preceded by self responses rather than group responses $(2,040.9 \mathrm{~ms}$ vs. $2,449.5 \mathrm{~ms}), t(35)=$ $2.00, p=.05$. The reaction time cutoffs affected $5.2 \%$ of the target item-level response times. The same pattern of results and significance emerged for the raw reaction time data $^{5}$ as well as various approaches to potential outliers, including using cutoffs of 2 or 3 standard deviations (both Windsorized and excluded values) as well as log transformations and reciprocal transformations (see Ratcliff, 1993).

Additional analyses were conducted to test whether any of the target cues (e.g., preferring the dog joke) directly affected reaction times or affected the interaction of similarity and dependent variable order on reaction times. The assumption that these effects would not be significant was borne out. There were no main effects of the joke, painting, and embezzlement case cues on target item reaction times nor were there any significant twoway (Cue $\times$ Similarity or Cue $\times$ Variable Order) or three-way

\footnotetext{
${ }^{5}$ Analyses of the raw reaction time results show the same pattern of findings, including a significant interaction in a $2 \times 2$ ANOVA, $F(1,70)=$ $6.15, p=.02$. Target responses were faster for participants in the dissimilarity condition when they were preceded by group responses rather than self responses $(1,838.0 \mathrm{~ms}$ vs. $2,210.0 \mathrm{~ms}), t(32)=1.81, p=.08$ Alternately, target responses were faster for participants in the similarity condition when they were preceded by self responses rather than group responses $(2,092.1 \mathrm{~ms}$ vs. $2,513.8 \mathrm{~ms}), t(35)=1.74, p=.09$.
} 


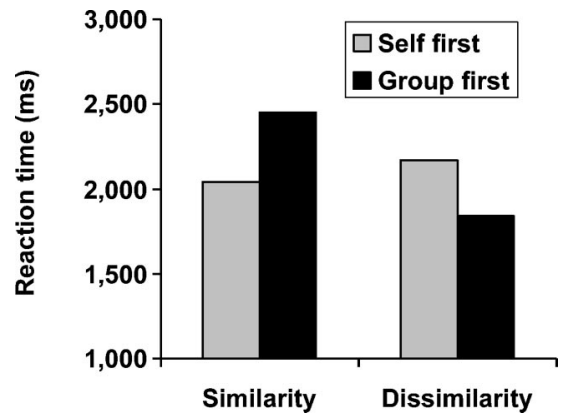

Figure 5. Target item reaction times as a function of similarity condition and self versus stereotype initial item, Study 3 .

(Cue $\times$ Similarity $\times$ Variable Order) interactions for any of the three cues.

\section{Discussion}

Using a new episode of behavior, a different similarity manipulation, and a novel stereotype, Study 3 replicated the results of Studies 1 and 2: Participants encouraged to believe they were similar to a target engaged in more projection and less stereotyping than those encouraged to believe they were different. Moreover, reaction time results from Study 3 provide evidence of these cognitive processes in action: Self responses best facilitated target responses in the similarity condition (consistent with projection), whereas stereotype responses best facilitated target responses in the dissimilarity condition (consistent with stereotyping). This pattern of reaction times suggests that perceivers were not simply seeking expedience but rather were sensitive to the appropriateness of projection and stereotyping given their sense of similarity to the target.

\section{General Discussion}

We are all mind readers-but how? Three studies provided support for this article's proposal about the sources of mind reading: Perceivers engaged in higher levels of projection and lower levels of stereotyping in mental state inferences when they perceived greater initial general similarity to targets. Evidence for these effects comes from both the content of the inferences as well as reaction time results regarding projection and stereotyping processes. Moreover, projection and stereotyping appeared to be negatively correlated, suggesting that the two could act as alternative inferential strategies, displacing one another depending on perceived similarity. Across these studies, similarity manipulations took advantage of perceivers' readiness to generalize similarity from limited cues, such as a shared taste in humor. When participants found they had such specific cues in common with targets (e.g., a shared preference for a painting by Klee over one by Kandinsky), they were considerably more likely to project their own desires and attitudes onto targets in domains ranging from romantic interactions to face-to-face business negotiations. When participants found they did not share such attributes with targets, they were more likely to rely on stereotypes of groups ranging from fraternity members to librarians.
The overall image that emerges from the present work, then, is of a mind reader whose shifts between readily applied inferential tools are guided not solely by expediency but also by assumptions related to their appropriateness: She expects others who initially seem to be similar to share her own thoughts, desires, and feelings, and she expects others who initially seem to be different to have thoughts, desires, and feelings typical of salient groups to which they belong. Such flexible and fast tools of social judgment no doubt bring benefits to perceivers. Just as surely, their use and combination pose risks for both perceivers and the perceived.

\section{Boundaries and Outstanding Issues}

The proposed model focuses on several sources of mind reading but does not address all routes nor all the conditions that prompt perceivers to shift between them (for a review, see Ames, in press-a). Other scholars have considered how the situational context surrounding behavior can be an important source of mental state inferences (e.g., Karniol \& Shomroni, 1999; Reeder et al., 2002; Trope, 1986). Elsewhere, work on analogic reasoning has suggested that third parties can serve as templates for new acquaintances (e.g., Chen, 2001), an approach that may extend to mental state inferences.

Another important source for mind reading is affective displays, especially those involving self-evaluative emotions (Tangney \& Fischer, 1995). This is behavior about behavior and outcomes (e.g., a remorseful look after spilling coffee on a colleague) and can signal much about the actor's attitude toward the given circumstances and his ongoing intentions (Ames, Johar, \& Kammrath, 2004). A more complete model of the mind reader's tool kit would address the place and use of situation information, analogic transfer, self-evaluative emotional displays, and other tools.

\section{Mechanisms: Application and Activation}

The reaction time results from Study 3 show that when similarity was highlighted, self responses best facilitated target responses, whereas when dissimilarity was highlighted, stereotype responses best facilitated target responses. These effects might be thought of as application effects (speedily employing activated constructs in inferences) in contrast to activation effects (the readiness with which perceivers can call on constructs). There are reasons to think both types of mechanisms may be at work in mental state inference. In particular, Kunda and colleagues' (Kunda et al., 2002; Kunda \& Spencer, 2003) work has suggested a stereotype activation effect: Those in the dissimilarity condition might have been inclined to view the entire episode through a stereotype's lens and have been faster to answer questions about the target's stereotype. It is less clear that a parallel self activation effect would emerge. On the one hand, there is evidence that different conceptions of the self can be activated or primed (e.g., Davis et al., 1996; Markus \& Kunda, 1986; Trafimow, Triandis, \& Goto, 1991). On the other hand, awareness of one's own mental states may be rapidly achieved under any condition, because of privileged access or an illusion of access that comes from self-expertise (e.g., Gopnik, 1993). 
The results of Study 3 reveal a stereotype activation effect but not a self activation effect. ${ }^{6}$ Those in the dissimilarity condition appeared ready to see the target through the lens of a stereotype, presumably as the scene unfolded, making them faster to judge what the stereotype suggested for the scene. However, activation was not the whole story: The extent to which self and stereotype activation facilitated target judgment depended on similarity. Perceivers were not simply effort minimizers who extended an incidentally activated construct to the target; rather, they appeared to be guided by how well the activated construct (self or stereotype) fit with their sense of similarity to the target.

\section{Perceived Similarity}

The present studies relied on overgeneralization to manipulate perceived similarity: Participants learned that they shared a few specific attributes with a target, and from this, they expected a broad correspondence between their own thoughts and the target's. Other sources of perceived similarity exist as well. In other work (Ames, in press-b), I have channeled perceivers' attention, asking them to describe either similarities to or differences from various target groups (similar to the hypothesis-testing mechanism described by Mussweiler, 2003). Even though the similarities or differences were self-generated, participants showed considerable divergence in subsequent measures of perceived similarity. Moreover, parallel to the results in the present article, participants asked to describe similarities showed greater projection and less stereotyping than those asked to describe differences. Elsewhere (Ames \& Iyengar, in press), I have found that perceptions of similarity are at least partly related to individual differences in general motivations-specifically, in needs for uniqueness (cf. Snyder \& Fromkin, 1980).

Overgeneralization, selective attention, and motivation may all have roles in perceptions of similarity. Given the potential importance of perceived similarity as a moderator of inferential strategies, such effects deserve to be better understood.

\section{Portraits of Projection and Stereotyping}

What do perceivers do when they do not stereotype? The sometimes implicit, sometimes explicit answer in much of the contemporary stereotyping literature seems to run along the lines, "They laboriously individuate the target, though only if they have the cognitive resources and motivation to do so." The present work does not question the importance of individuation, but it does suggest that the picture should be broadened to include projection as a potential low-effort strategy that perceivers might use in place of stereotyping. However, doing so complicates matters, because chalking stereotyping up to laziness or "miserliness" fails to explain when perceivers might project rather than stereotype. Thus, richer models are needed that delineate when perceivers might individuate, stereotype, and project. The present model may be a start in this direction.

Another point is worth making regarding stereotyping: Perceptions of self-other similarity are only one of three potentially relevant similarity judgments. From a balance theory perspective, self, other, and group (i.e., the other's relevant group) may each be compared, yielding self-other similarity ("Is he like me?"), selfgroup similarity ("Are they like me?"), and other-group typicality
("Is he like them?"). When one or two of these are known, perceivers will likely use them to intuit those unknown. Accordingly, Study 1 showed that self-group similarity partially predicted self-other similarity. In Study 3, typicality was measured (whether Michael was a typical investment banker) after the similarity manipulation. Those in the similarity (vs. dissimilarity) condition showed not only higher ratings of self-other similarity but also lower ratings of other-group typicality. The target shifted, as it were, away from the group and toward the self. In short, the present model meshes with balance theory to suggest a characterization of perceived dissimilarity: When a gulf opens between the self and other, a stereotype may rush in. Perceived similarity might be described likewise: When a gulf opens between the other and a stereotype, the self may rush in.

Just as models of stereotyping ought not to ignore projection, models of projection ought not to ignore stereotyping. Again, we might ask of this literature what perceivers do if they do not project. Clement and Krueger (2002) noted that few moderators of projection have been documented. Different pockets of work have suggested that self-enhancement or false uniqueness might emerge as alternatives to projection (for a review, see Krueger, 2000). Yet stereotypes have not been granted much of a role in models of projection, false consensus, or naive realism. Exploring when and how projection gives way to stereotyping may yield not only a better description of projection's limits but also a better description of the nature of projection itself.

\section{Accuracy and Distortion}

Accuracy in mind reading has received increased attention in recent years, and scholars have uncovered mounting evidence of its importance for social and relational effectiveness (see, e.g., Ickes, 1997; Mayer, Caruso, \& Salovey, 1999). Yet much of this research has lacked a framework for systematically describing the ways in which perceivers may err or the range of tools perceivers can leverage for accuracy. The present work does not fill this need conclusively, but it helps pave the way for such frameworks. In the proposed model, the accurate mind reader is one who, when unable to make inferences from observable behaviors, effectively assesses her similarity to the target. When this is high, she deservedly projects her own attitudes. When it is low, she turns to accurate stereotypes as a starting point.

These same processes can be inverted for a portrait of distortions. First, the perceiver may fail to read available behavior and thus turn to top-down inferential tools when bottom-up analyses would yield better insights. Next, the perceiver may misdiagnose

\footnotetext{
${ }^{6}$ For participants encountering group items first, those in the dissimilarity condition responded on average more quickly than those in the similarity condition $(3,969.3 \mathrm{~ms}$ vs. $4,788.1 \mathrm{~ms}), t(34)=2.21, p=.03$. For participants encountering self items first, there was no significant effect of similarity vs. dissimilarity on self response times $(4,143.8 \mathrm{~ms}$ vs. $3,856.2$ $\mathrm{ms}), t(32)=0.74, p=.47$. These results use the previously discussed cutoffs, though the same pattern of results emerges for various approaches to potential outliers. Raw reaction time results show the same effects: For group responses, those in the dissimilarity condition responded on average more quickly than those in the similarity condition (3,930.9 ms vs. 4,949.0 $\mathrm{ms}), t(34)=2.23, p=.03$; for self responses, there was not a significant difference $(4,124.3 \mathrm{~ms}$ vs. $3,897.6 \mathrm{~ms}), t(32)=0.55, p=.59$.
} 
similarity, perhaps by overgeneralizing from limited cues. If similarity is underestimated, or even if it is justifiably seen as low, the perceiver may apply a baseless or inappropriate stereotype. If similarity is overestimated, the perceiver may engage in more projection than is warranted. Even if similarity is justifiably seen as high, the perceiver may project but fail to truly understand her own beliefs, desires, and feelings. In other words, projection may only be as valid as the introspection on which it stands-and people's introspections are notoriously imperfect (Van Boven \& Loewenstein, in press; Wilson, 2002). This map of inaccuracy may help organize research on the nature and antecedents of these distortions and their relative contribution to prejudice, harmful conflict, and other unwanted social outcomes.

\section{Final Thoughts}

Over the course of history, some great thinkers have declared that the challenge of intuiting what others think, want, and feelthe so-called "problem of other minds"-may be intractable in principle, but in the practical course of ordinary life, people solve this problem countless times a day, at least to their own satisfaction. In this article, I consider some of these everyday solutions. There is every reason to think that perceivers frequently stereotype and also frequently project - and that there are lawful regularities in how they combine and trade off these inferential tools to read minds. Models that attempt to span this tool kit promise to provide a richer understanding of social judgment in general and of the ordinary magic of mind reading.

\section{References}

Ames, D. R. (in press-a). Everyday solutions to the problem of other minds. In B. F. Malle \& S. D. Hodges (Eds.), Other minds. New York: Guilford Press.

Ames, D. R. (in press-b). Strategies for social inference: Projecting to the similar and stereotyping the different in attribute prevalence judgments. Journal of Personality and Social Psychology.

Ames, D. R., \& Iyengar, S. S. (in press). Appraising the unusual: Framing effects and moderators of uniqueness-seeking and social projection. Journal of Experimental Social Psychology.

Ames, D. R., Johar, G. V., \& Kammrath, L. K. (2004). The impact of affective displays on impression formation: I know what you're like when I see how you feel. Manuscript submitted for publication.

Brewer, M. B. (1988). A dual process model of impression formation. In R. S. Wyer Jr. \& T. K. Srull (Eds.), Advances in social cognition (Vol. 1, pp. 1-36). Hillsdale, NJ: Erlbaum.

Bruner, J. (1990). Acts of meaning. Cambridge, MA: Harvard University Press.

Chen, S. (2001). The role of theories in mental representations and their use in social perception: A theory-based approach to significant-other representations and transference. In G. B. Moskowitz (Ed.), Cognitive social psychology: The Princeton Symposium on the Legacy and Future of Social Cognition (pp. 125-142). Mahwah, NJ: Erlbaum.

Clement, R. W., \& Krueger, J. (2002). Social categorization moderates social projection. Journal of Experimental Social Psychology, 38, 219231

Coats, S., Smith, E. R., Claypool, H. M., \& Banner, M. J. (2000). Overlapping mental representations of self and in-group: Reaction time evidence and its relationship with explicit measures of group identification. Journal of Experimental Social Psychology, 36, 304-315.

Davis, M. H., Conklin, L., Smith, A., \& Luce, C. (1996). Effect of perspective taking on the cognitive representation of persons: A merging of self and other. Journal of Personality and Social Psychology, 70, $713-726$.

Dennett, D. C. (1987). The intentional stance. Cambridge, MA: MIT Press Empirisoft Corporation. (2004). MediaLab v2004 [Computer software] New York: Author.

Fiske, S. T., \& Neuberg, S. L. (1990). A continuum of impression formation, from category-based to individuating processes: Influences of information and motivation on attention and interpretation. In M. P. Zanna (Ed.), Advances in experimental social psychology (Vol. 23, pp. 1-74). New York: Academic Press.

Galinsky, A. D., \& Moskowitz, G. B. (2000). Perspective-taking: Decreasing stereotype expression, stereotype accessibility, and in-group favoritism. Journal of Personality and Social Psychology, 78, 708-724.

Gilbert, D. T., \& Hixon, J. G. (1991). The trouble of thinking: Activation and application of stereotypic beliefs. Journal of Personality and Social Psychology, 60, 509-517.

Goldman, A. (2001). Desire, intention, and the simulation theory. In B. F. Malle, L. J. Moses, \& D. A. Baldwin (Eds.), Intentions and intentionality: Foundations of social cognition (pp. 207-224). Cambridge, MA: MIT Press.

Gopnik, A. (1993). How we know our minds: The illusion of first-person knowledge of intentionality. Behavioral and Brain Sciences, 16, 1-15, $90-101$.

Gopnik, A., \& Meltzoff, A. N. (1997). Words, thoughts, and theories. Cambridge, MA: MIT Press.

Heider, F. (1958). The psychology of interpersonal relations. Hillsdale, NJ: Erlbaum.

Hugenberg, K., \& Bodenhausen, G. (2003). Facing prejudice: Implicit prejudice and the perception of facial threat. Psychological Science, 14, 640-643.

Ickes, W. (1997). Empathic accuracy. New York: Guilford Press.

Jones, E. E., \& Davis, K. E. (1965). From acts to dispositions: The attribution process in person perception. In L. Berkowitz (Ed.), Advances in experimental social psychology (Vol. 2, pp. 219-266). New York: Academic Press.

Kammrath, L., Mendoza-Denton, R., \& Mischel, W. (2004). What's in a trait? Mental states and If . . then ... profiles in folk theories of traits. Manuscript submitted for publication.

Karniol, R., \& Shomroni, D. (1999). What being empathic means: Applying the transformation rule approach to individual differences in predicting the thoughts and feelings of prototypic and nonprototypic others. European Journal of Social Psychology, 29, 147-160.

Kelley, H. H. (1973). The processes of causal attribution. American Psychologist, 28, 107-128.

Klein, S. B., Loftus, J., Trafton, J. G., \& Fuhrman, R. W. (1992). Use of exemplars and abstractions in trait judgments: A model of trait knowledge about the self and other. Journal of Personality and Social Psychology, 63, 739-753.

Krueger, J. (2000). The projective perception of the social world: A building block of social comparison processes. In J. Suls \& L. Wheeler (Eds.), Handbook of social comparison: Theory and research (pp. 323351). New York: Kluwer Academic/Plenum Publishers.

Kruglanski, A. W. (1975). The endogenous-exogenous partition in attribution theory. Psychological Review, 82, 387-406.

Kunda, Z., Davies, P. G., Adams, B. D., \& Spencer, S. J. (2002). The dynamic time course of stereotype activation: Activation, dissipation, and resurrection. Journal of Personality and Social Psychology, 82, 283-299.

Kunda, Z., \& Spencer, S. (2003). When do stereotypes come to mind and when do they color judgment? A goal-based theoretical framework for stereotype activation and application. Psychological Bulletin, 129, 522 544.

LaughLab's World's Funniest Joke Project. (n.d.). Retrieved September 1, 2003, from www.laughlab.co.uk 
Malle, B. F. (2001). Folk explanations of intentional action. In B. F. Malle, L. J. Moses, \& D. A. Baldwin (Eds.), Intentions and intentionality: Foundations of social cognition (pp. 265-286). Cambridge, MA: MIT Press.

Markus, H., \& Kunda, Z. (1986). Stability and malleability of the selfconcept. Journal of Personality and Social Psychology, 51, 858-866.

Mayer, J. D., Caruso, D. R., \& Salovey, P. (1999). Emotional intelligence meets traditional standards for an intelligence. Intelligence, 27, 267-298.

Mussweiler, T. (2003). Comparison processes in social judgment: Mechanisms and consequences. Psychological Review, 110, 472-489.

Newtson, D. (1973). Attribution and the unit of perception of ongoing behavior. Journal of Personality and Social Psychology, 28, 23-38.

Pennington, N., \& Hastie, R. (1992). Explaining the evidence: Tests of the story model for juror decision making. Journal of Personality and Social Psychology, 62, 189-206.

Ratcliff, R. (1993). Methods for dealing with reaction time outliers. Psychological Bulletin, 114, 510-532.

Read, S. J., Jones, D. K., \& Miller, L. C. (1990). Traits as goal-based categories: The role of goals in the coherence of dispositional categories. Journal of Personality and Social Psychology, 58, 1048-1061.

Reeder, G. D., Kumar, S., Hesson-McInnis, M., \& Trafimow, D. (2002). Inferences about the morality of an aggressor: The role of perceived motive. Journal of Personality and Social Psychology, 83, 789-803.

Ross, L., Greene, D., \& House, P. (1977). The false consensus effect: An egocentric bias and social perception and attribution processes. Journal of Experimental Social Psychology, 13, 279-301.

Ross, L., \& Ward, A. (1996). Naive realism: Implications for social conflict and misunderstanding. In T. Brown, E. Reed, \& E. Turiel (Eds.), Values and knowledge (pp. 103-135). Hillsdale, NJ: Erlbaum.

Sagar, H. A., \& Schofield, J. W. (1980). Racial and behavioral cues in
Black and White children's perceptions of ambiguously aggressive acts. Journal of Personality and Social Psychology, 39, 590-598.

Shaver, K. G. (1985). The attribution of blame: Causality, responsibility, and blameworthiness. New York: Springer-Verlag.

Smith, E. R., \& Henry, S. (1996). An in-group becomes part of the self: Response time evidence. Personality and Social Psychology Bulletin, $22,635-642$.

Snyder, C. R., \& Fromkin, H. L. (1980). Uniqueness: The human pursuit of difference. New York: Plenum Press.

Sutton, R. M., \& McClure, J. (2001). Covariational influences on goalbased explanation: An integrative model. Journal of Personality and Social Psychology, 80, 222-236.

Tangney, J. P., \& Fischer, K. W. (Eds.). (1995). Self-conscious emotions: The psychology of shame, guilt, embarrassment, and pride. New York: Guilford Press.

Trafimow, D., Triandis, H. C., \& Goto, S. G. (1991). Some tests of the distinction between the private self and the collective self. Journal of Personality and Social Psychology, 60, 649-655.

Trope, Y. (1986). Identification and inferential processes in dispositional attributions. Psychological Review, 93, 239-257.

Trope, Y. (1989). Levels of inference in dispositional judgment. Social Cognition, 7, 296-314.

Van Boven, L., \& Loewenstein, G. (in press). Varieties of social projection. In M. Alicke, D. Dunning, \& J. Krueger (Eds.), The self in social perception. New York: Psychology Press.

Weiner, B. (1995). Judgments of responsibility. New York: Guilford Press. Wellman, H. M. (1990). The child's theory of mind. Cambridge, MA: MIT Press.

Wilson, T. (2002). Strangers to ourselves: Discovering the adaptive unconscious. Cambridge, MA: Harvard University Press.

\section{Appendix}

\section{Embezzlement Case Used in Study 3, Adapted From Pennington and Hastie (1992)}

David Graves has been charged with the embezzlement of $\$ 6,500$, taken from the vault of a large bank. Graves was employed as a security guard in the bank's vault at the time. The janitor at the bank testified that he saw Graves place money in a bank money bag at 5 p.m. on the day in question. The janitor did not report the incident right away. The personnel manager testified that the janitor had complained about Graves being given preferential treatment prior to the incident.

The police found an empty bank money bag in Graves's apartment. Graves claimed that he used the money bag to hold change for the coin-operated laundry machines in his apartment building. The police also found $\$ 4,000$ in cash in a box beneath the floor boards of Graves's apartment. Graves claimed that the money was a reserve for medical emergencies because he had once been refused treatment because of a cash advance.

Graves was served with a repossession notice by debt collectors four days before the crime. However, receipts from the loan company dated two days before the crime were produced in evidence.

Graves testified that he left work early on the day in question in order to get a haircut. A close friend of Graves testified that Graves had been in his barber shop at 5 p.m. on the day in question.

Note. From "Explaining the Evidence: Tests of the Story Model for Juror Decision Making," by N. Pennington and R. Hastie, 1992, Journal of Personality and Social Psychology, 62, p. 205. Copyright 1992 by the American Psychological Association. Adapted with permission of the authors.
Received April 24, 2000

Revision received April 19, 2004

Accepted April 28, 2004 